\title{
Designing an Information System to support the implementation of the Retrieval Practice Method
}

\section{Perancangan Sistem Informasi untuk mendukung penerapan Metoda Retrieval Practice}

\author{
Witarto Adi Winoto ${ }^{1 *}$, Irvania Sukma Kumala ${ }^{2}$
}

\begin{abstract}
The Retrieval Practice method was developed based on a memory model. In this study, the characteristics of deep rehearsal, including semantic processing accompanied by pictures are the basis for making quiz questions. The application of the Retrieval Practice method requires the support of Information Systems. Focus Group Discussions discuss aspects of repetition in learning. The aim of supporting the application of the Retrieval Practice method is expected to be able to improve student competencies, especially in terms of maturing students' knowledge and understanding. Data is measured from testing semester 2-2018 and semester 1-2019. Conclusion: Cognitive understanding for teachers will help students understand knowledge, understanding, analysis and synthesis into their memories..
\end{abstract}

Keywords

information systems, elaborative rehearsal, quiz questions, repetition, multi-perspective quizzes

\begin{abstract}
Abstrak
Metode Retrieval Practice dikembangkan berdasarkan model memori. Dalam penelitian ini, karakteristik deep rehearsal, termasuk pemrosesan semantik yang disertai gambar adalah dasar untuk membuat pertanyaan kuis. Penerapan metode Retrieval Practice memerlukan dukungan Sistem Informasi. Diskusi Kelompok Terfokus membahas aspek pengulangan dalam pembelajaran. Tujuan mendukung penerapan metode Retrieval Practice ini diharapkan dapat meningkatkan kompetensi mahasiswa terutama dalam hal mematangkan pengetahuan dan pemahaman para mahasiswa. Data diukur dari pengujian semester 2-2018 dan Semester 1-2019. Kesimpulan : pemahaman kognitif bagi dosen akan membantu mahasiswa memahami pengetahuan, pemahaman, analisis dan sintesis ke dalam ingatan mereka.
\end{abstract}

Kata Kunci

sistem informasi, latihan elaboratif, pertanyaan kuis, pengulangan, kuis multi perspektif

1 Program Studi Teknik Informatika, Politeknik Kota Malang, Jalan Raya Tlogowaru No 3 Malang Jawa Timur, 65133 (tlp: (0341) 754088; fax: (0341) 754088;

2 Program Studi Teknik Telekomunikasi, Politeknik Kota Malang, Jalan Raya Tlogowaru No 3 Malang Jawa Timur, 65133 (tlp: (0341) 754088; fax: (0341) 754088;

*witart@gmail.com

Submitted : December 08, 2019. Accepted : December 18, 2019. Published : January 15, 2020. 


\section{PENDAHULUAN}

Ingatan atau memori merupakan bagian penting bagi manusia. Di situ pengetahuan seseorang ditempatkan. Sementara, pendidikan adalah upaya membentuk bangunan pengetahuan dan pemahaman para mahasiswa, agar memiliki kompetensi. Pembentukan bangunan ini, secara berkala memerlukan penilaian, yang berpengaruh pada kemudahan pemanfaatannya. Penelusuran konsep kognitif dalam penelitian ini adalah untuk memperoleh pola yang sesuai bagi pembentukan naskah soal dalam penilaian. Penerapan dukungan sistem informasi sangat diperlukan. Pengkajian beberapa konsep kognitif, seperti latihan elaboratif dan serta ranah kognitif taksonomi Bloom, serta pengembangannya berbentuk multi perspektif, digunakan untuk membentuk naskah soal.

Urgensi penelitian ini penting untuk dilakukan, mengingat banyaknya peserta ujian ulangan atau ujian perbaikan. Mahasiswa sering tidak fokus kepada materi kuliahnya. Perlunya mengembangkan metoda pembelajaran dengan pendekatan Quiz and Recall, yang dalam penelitian ini disebut Retrieval Practice, agar dapat mendukung pencapaian tujuan khusus. Sementara pembentukan kompetensi setiap kelas hanya mencapai rata-rata 15 persen.

Pemanfaatan konsep kognitif untuk pembuatan soal yang mendalam, pemanfaatan sistem informasi untuk mengulang dan mengarsipkan hasil pengujian mahasiswa, sangat diperlukan dalam penerapan Retrieval Practice. Bagaimana menyusun soal dengan merujuk konsep psikologi kognitif, yang menggambarkan soal-soal dengan analisis, sintesis (create), penalaran, pemahaman, penerapan, maupun evaluasi ataupun dengan metoda rehearsal lainnya?. Bagaimana cara membuat alat uji kuis berbentuk sistem informasi untuk mendukung pelaksanakan konsep Retrieval Practice, yang memanfaatkan kuis dan ujian ?. Bagaimana mengukur validitas nilai kuis terhadap nilai ujian, untuk menilai peran proses retrieval practice?.

Pustaka penelitian ini didasarkan kepada model memori Atkinson-Shifrin, (1968), lihat Gambar 1. Yang kemudian dikembang-kan di antaranya oleh Pooja Agarwal PhD, dan kawankawan. Informasi yang tersimpan pada memori dapat berupa hal elementer, dapat pula berupa pola (pattern), maupun bentuk pengembangan.

Melalui penelitian ini diharapkan akan diperoleh metoda yang dapat memberikan latihan berfikir bagi mahasiswa, terutama dalam memasukkan informasi isi matakuliah untuk mencapai long-term memory, sehingga memberikan hasil aktivitas belajar yang lebih baik. Latihan berfikir ini akan didukung Sistem Informasi yang sesuai.

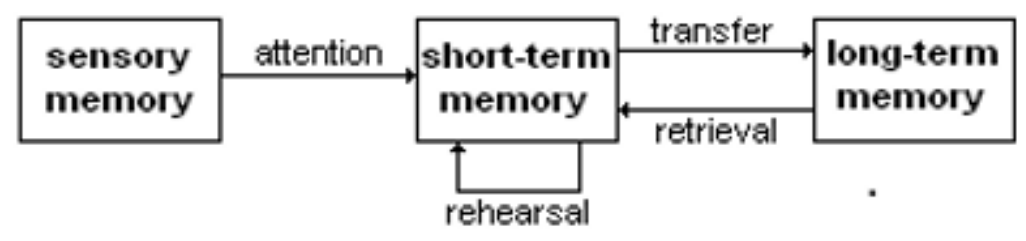

Gambar 1. Model Memori Atkinson-Shifrin

\section{Memori Sensorik,}

Merupakan memori sensor manusia seperti yang ada pada penglihatan, pendengaran, rasa, sentuhan, penciuman dapat dikatakan sensitif terhadap rangsangan yang sangat luas. Memori ini hanya merespons sebagian kecil dari semua stimulasi yang tersedia pada waktu tertentu; sebagian besar informasi yang tersedia dalam rangsangan ini tidak pernah diproses - yaitu, tidak pernah menjadi bagian struktur kognitif kita. 


\section{Memori jangka pendek.}

Informasi yang menyentuh memori sensorik mengikuti perhatian; dan menjadi stimulus sebelum manusia memperhatikannya. Ketika manusia memperhatikan stimulus (atau sadar adanya stimulus), informasi ini akan terekam masuk memori jangka pendek. Memori jangka pendek termasuk apa yang ada dalam kesadaran langsung dalam waktu tertentu. Ini adalah semacam alas untuk berpikir; untuk alasan ini, memori jangka pendek sering disebut memori kerja.

\section{Model Memori jangka panjang.}

Memori ini mencakup semua informasi yang diingat seseorang yang relatif stabil tentang dunia - apa yang kita ketahui tetapi tidak ada dalam kesadaran langsung.

\section{Latihan (Rehearsal)}

Latihan adalah proses memori yang melibatkan pengulangan, penting untuk menjaga informasi dalam memori jangka pendek dan mentransfernya ke memori jangka panjang. Latihan melibatkan pengulangan. Strategi latihan yang paling sederhana adalah untuk menyatakan materi (seperti, lima, lima, lima, satu, dua, satu, dua) berulang-ulang sampai tampaknya tidak mungkin akan lepas dari ingatan. [5].

\section{Retrieval Practice.}

Menurut Dr. Pooja Agarwal, "Retrieval practice" adalah strategi pembelajaran manusia fokus untuk mendapatkan informasi dari otaknya. Melalui tindakan pengambilan, atau memanggil informasi ke pikiran, ingatan manusia untuk informasi itu akan diperkuat dan melupakan kemungkinan kecil terjadinya kesalahan. Retrieval Practice adalah alat yang ampuh untuk meningkatkan pembelajaran tanpa teknologi, uang, atau waktu di dalam kelas.

Dalam Retrieval practice dengan sengaja mengingat informasi memaksa manusia untuk menarik pengetahuannya "keluar" dan memeriksa apa yang diketahuinya. Justru "perjuangan" atau tantangan inilah yang meningkatkan ingatan dan pembelajaran manusia dengan mencoba mengingat informasi, manusia melatih atau memperkuat ingatannya, serta dapat mengidentifikasi kesenjangan dalam pembelajaran. [1][2][6][7]

\section{Validitas Alat Ukur.}

Menurut Prof. Suharsimi Arikunto, sebuah tes (untuk mengukur kompetensi) memiliki validitas, jika sesuai kriterium. Artinya sejajar antara hasil uji dengan korelasi product moment-nya Pearson, khususnya dengan angka kasar. [8]

Formula korelasi antara product moment dan angka kasar

$$
r_{x y}=\frac{N \sum X Y-\left(\sum X\right)\left(\sum Y\right)}{\sqrt{\left\{N \sum X^{2}-\left(\sum X\right)^{2}\right\}\left\{N \sum Y^{2}-\left(\sum Y\right)^{2}\right\}}}
$$

Legenda untuk formula (1)

Validitas data pada pengukuran A

$\mathrm{rxY}=$ Koefisien korelasi antara variabel $\mathrm{X}$ dan variabel $\mathrm{Y}$

Variabel X merupakan nilai sekelompok mahasiswa kelompok I pada Pengukuran A.

Variabel Y merupakan nilai kelompok I pada Pengukuran A, untuk waktu yang lain..

\section{Level Processing.}

Menurut Craik - Lockhart (1972) : Stimulus yang sangat akrab dan bermakna misalnya berbentuk kombinasi gambar dan kalimat akan diproses ke tingkat yang lebih dalam dan lebih cepat daripada stimuli yang kurang bermakna dan akan dipertahankan dengan baik. [10][11]. Rumus peningkatan kompetensi dari data yang sudah divalidasi, sebagai berikut: [8]

$$
P_{A B}=\frac{A-B}{A} \times 100 \%
$$




\section{METODE PENELITIAN}

\section{Mengkaji konsep Retrieval Practice}

Metoda pertama adalah mengkaji konsep Retrieval Practice dengan perangkat lunak yang sudah ada. Objek yang diteliti adalah mengukur kompetensi mahasiswa dengan pengulangan. Pengujian dilakukan pada awal kuis.

\section{Pembuatan soal dengan pendekatan latihan elaboratif dan multi perspektif}

Pembuatan soal dikembangkan dengan pendekatan latihan elaboratif dan multi perspektif. Objek yang diteliti adalah seberapa jauh pengaruh latihan elaboratif dan multi perspektif. Pengujian dilakukan pada kuis kedua, ketiga serta pada Ujian Tengah Semester. Di sini soal kuis tidak sepenuhnya sama dengan di kuis awal.

\section{Merancang Sistem Informasi}

Menggunakan metoda prototyping, merancang Sistem Informasi yang baru, berdasarkan hasil pengkajian konsep Retrieval Practice, serta pengembangan dan pengujian dengan soal multi perspektif. Objek yang diteliti adalah aplikasi Kahoot dan aplikasi Moodle, serta mencoba merancang aplikasi yang sesuai dengan menggunakan server pada situs sartemplek.com.

\section{Flowchart Pengujian dengan Retrieval Practice}

Untuk pengujian Retrieval Practice perlu dipahami metoda penerapannya.

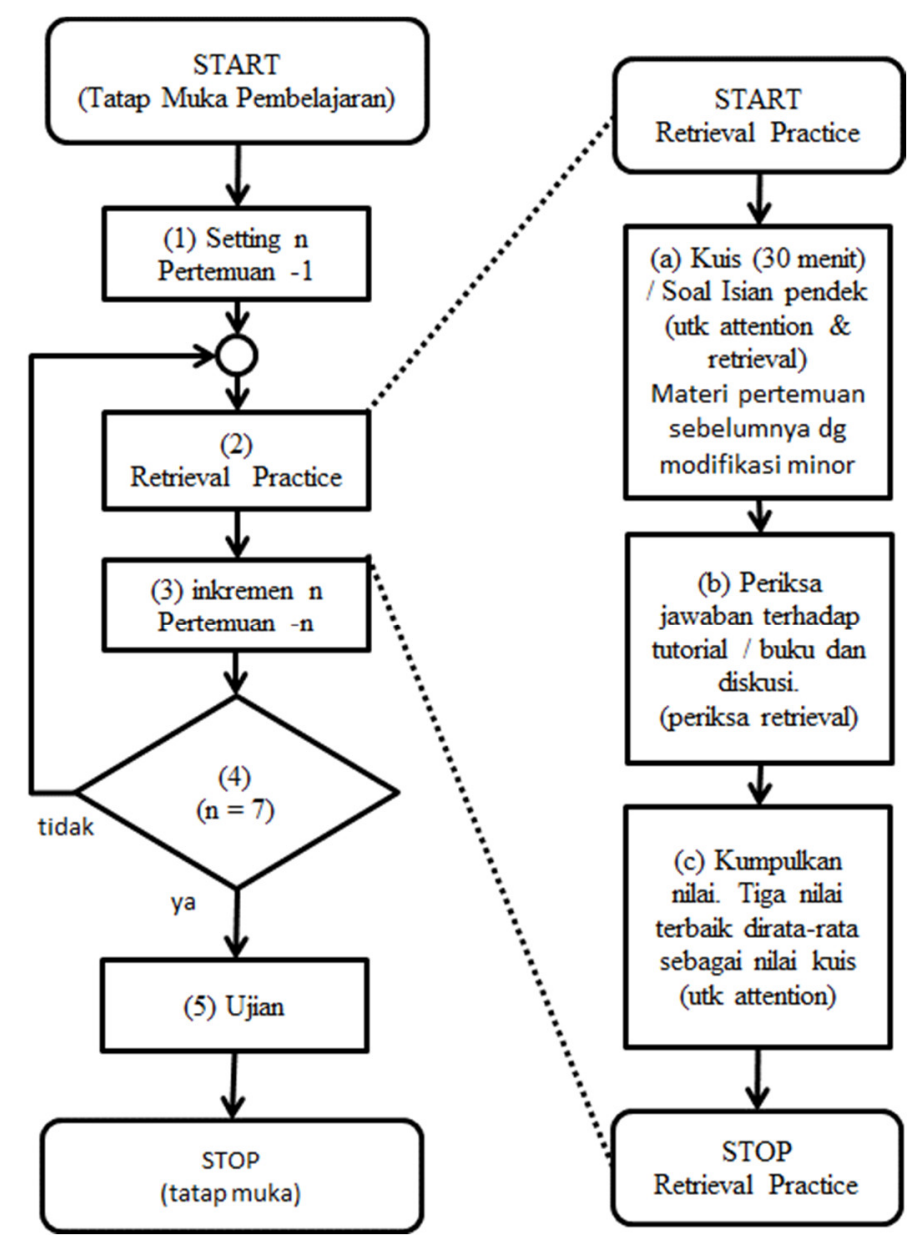

Gambar 2. Flowchart Pengujian dengan Retrieval Practice 


\section{Tabel 1. Pembuatan soal dengan pendekatan latihan elaboratif dan multi perspektif}

\begin{tabular}{|l|l|}
\hline \\
Gambar 3. Kereta Tezgam Express terbakar
\end{tabular}

Penyajian soal dengan kombinasi gambar, bahkan video dan narasi kata, akan mudah dikenal dan dipahami oleh mahasiswa.

Gambar pertama menyajikan peristiwa tragedi kebakaran kereta di Pakistan yang terjadi 31 Oktober 2019 yang lalu. Gambar diberikan dalam bentuk sketsa. Kemudian dengan pendekatan recall, dalam berberapa bentuk perspektif, mahasiswa diarahkan ke pemikiran pengenalan, pemahaman, analisis, sintesis dan evaluasi.

Contoh pertanyaan untuk soal dengan gambar 3.

Perspektif 1 (kerangka berita, $5 \mathrm{~W}+1 \mathrm{H}$ )

Jika melihat bentuk berita, dengan kerangka $5 \mathrm{~W}+1 \mathrm{H}$, apa yang kurang pada berita tersebut
a. Where
b. Why
c. Who
d. When

Perspektif 2 (wisdom)

Menurut Anda, kebijakan (wisdom) yang seperti apa yang sebaiknya diusulkan agar mencegah terulangnya kejadian seperti pada berita 0003 itu ?

a. perlu dibuat larangan menumpang kereta api, karena mudah terbakar

b. penumpang kereta harus banyak

c. perlu dibuat larangan bagi penumpang yang membawa zat yang mudah meledak

d. perlu dibuat larangan bagi penumpang walau tanpa pengawasan

Perspektif 3 (analisis root cause)

Kebakaran kereta api di Pakistan terjadi disebabkan oleh
a. tabung gas meledak
b. tabung gas macet
c. korsleting listrik
d. kayu bakar 
Perspektif 4 (analisis root cause)

Kebakaran kereta semakin parah karena

a. minyak goreng yang digunakan penumpang ikut terbakar

b. minyak goreng dapat memadamkan api

c. tiupan angin semakin kencang

d. tiupan angin dapat memadamkan kebakaran

Setidaknya terdapat 4 perspektif yang dapat dikembangkan dari gambar 3. Sementara pada gambar 4, perspektif dapat dikembangkan untuk analisis komponen pesawat, analisis kebutuhan safety (keselamatan pesawat), serta analisis atau sintesis pengembangan wisdom agar pesawat mainan tidak berbahaya bagi manusia yang berada di bawahnya.

\section{Metoda prototyping}

Untuk pengembangan Sistem Informasi dapat dilihat pada gambar 5. Pengembangan menggunakan metoda prototyping (Gambar 3), merupakan metoda membuat program dari bentuk kecil, lalu membesar menuju lengkap sesuai hasil analisis kebutuhan.

Terdapat 6 tahapan prototyping dalam penelitian ini.

Prototype 1.

Mendeteksi kebutuhan melalui bantuan Kahoot. Bahasa yang digunakan javascript.

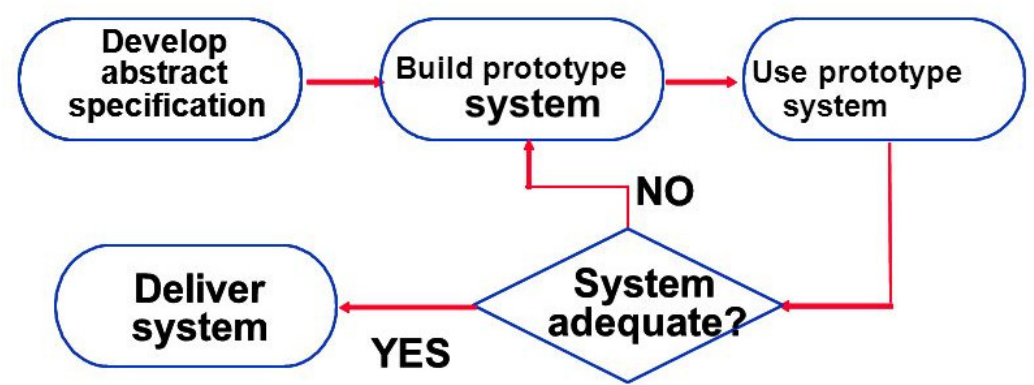

Gambar 5. Diagram tahapan Prototyping perencanaan sistem informasi

Prototype 2 .

Kahoot ternyata tidak memberikan hasil invidual layaknya nilai kuis atau ujian di sekolah, namun lebih kepada kebenaran dan kecepatan respon siswa yang menjawab. Aplikasi login mulai dibuat.

Prototype 3

Mulai membuat aplikasi dengan tabel data mysql dan PHP, mengingat kelemahan javascript tidak bisa multipage maupun penyimpanan ke tabel.

Prototype 4

Mulai hosting aplikasi. Mempelajari fungsionalitas yang ada pada moodle.

Pengujian Retrieval Practice dengan bantuan Moodle.

Prototype 5

Pembuatan modul Acak record dan pilihan soal.

Prototype 6

Uji Integrasi modul program keseluruhan 


\section{HASIL DAN PEMBAHASAN}

\section{Hasil}

Pada pengujian dengan Kahoot, analisis hasilnya sebagai berikut : Minat mahasiswa terhadap Kuis meningkat, Terdapat peningkatan hasil pengujian, pada session berikutnya. Proses kognitif rehearsal dan retrieval berjalan dengan baik. Soal yang diberikan dimulai dari yang bersifat sederhana, pengenalan istilah, pengenalan instruksi HTML dan Javascript. Kemudian beberapa nomor soal diulang.

Pada Aplikasi Kahoot belum diterapkan metoda latihan elaborative, Pada Pengujian dengan Moodle dilakukan perhitungan Validitas. Hasil Pengukuran Validitas nilai Kuis yang digunakan untuk melaksanakan Retrieval Practice terhadap nilai UTS matakuliah Dasar Sistem Informasi kelas TI-2019

Tabel 2. Pengukuran Validitas nilai kuis 1 terhadap nilai UTS kelas DSI TI-2019

\begin{tabular}{|c|c|c|c|c|c|}
\hline Peserta & Kuis $1(\mathrm{X})$ & UTS $(\mathrm{Y})$ & $\mathrm{X}^{2}$ & $\mathrm{Y}^{2}$ & $\mathrm{XY}$ \\
\hline PLTKM90001 & 7 & 84 & 49 & 7056 & 588 \\
\hline PLTKM90002 & 5 & 84 & 25 & 7056 & 420 \\
\hline PLTKM90003 & 3 & 84 & 9 & 7056 & 252 \\
\hline PLTKM90004 & 3 & 64 & 9 & 4096 & 192 \\
\hline PLTKM90005 & 4 & 84 & 16 & 7056 & 336 \\
\hline PLTKM90006 & 6 & 84 & 36 & 7056 & 504 \\
\hline PLTKM90007 & 7 & 96 & 49 & 9216 & 672 \\
\hline PLTKM90008 & 6 & 92 & 36 & 8464 & 552 \\
\hline PLTKM90009 & 6 & 88 & 36 & 7744 & 528 \\
\hline PLTKM90010 & 4 & 56 & 16 & 3136 & 224 \\
\hline PLTKM90011 & 6 & 76 & 36 & 5776 & 456 \\
\hline PLTKM90012 & 7 & 88 & 49 & 7744 & 616 \\
\hline PLTKM90013 & 6 & 84 & 36 & 7056 & 504 \\
\hline PLTKM90014 & 5 & 84 & 25 & 7056 & 420 \\
\hline PLTKM90015 & 5 & 88 & 25 & 7744 & 440 \\
\hline PLTKM90016 & 4 & 92 & 16 & 8464 & 368 \\
\hline PLTKM90017 & 6 & 84 & 36 & 7056 & 504 \\
\hline PLTKM90020 & 4 & 84 & 16 & 7056 & 336 \\
\hline PLTKM90021 & 6 & 60 & 36 & 3600 & 360 \\
\hline PLTKM90023 & 4 & 76 & 16 & 5776 & 304 \\
\hline
\end{tabular}

$\mathrm{r}_{\mathrm{xy}}$ kuis-1/UTS untuk kelas TI $2019=0.349955487$

Nilai Rata-rata kuis-1 : 50.7, dari 20 mahasiswa

\section{Pembahasan}

Merujuk Tabel 2, Tabel3 dan tabel 4, Nilai Validitas menurut perspektif perbandingan Kuis terhadap UTS rendah ketika kuis 1, kemudian naik ketika kuis 2, dan menurun lagi ketika kuis 3. Rendahnya validitas di kuis 1 (tabel 2), kemungkinan disebabkan mahasiswa masih kaget karena menghadapi kuis pertama kali, serta masih banyak yang belum menguasai sistem informasi. Di antaranya, mereka masih belum bisa membedakan antara data dan informasi.

Validitas di kuis 3 terhadap UTS menurun, karena beberapa mahasiswa mencapai nilai tinggi (100) ketika kuis 3, dan sedikit menurun ketika mengikuti UTS.

Yang menarik di sini, pada kuis 3 dan UTS, nilai hasil pengujian mahasiswa masih bertahan di nilai di atas 80, ketika diberikan soal dengan pendekatan latihan elaboratif dan multi perspektif. Diharapkan hal ini menandakan bahwa bangunan pengetahuan dan pemahaman mahasiswa sudah mulai terbentuk. 
Tabel 3. Pengukuran Validitas nilai kuis 2 terhadap nilai UTS kelas DSI TI-2019

\begin{tabular}{|c|c|c|c|c|c|}
\hline Peserta & Kuis $2(\mathrm{X})$ & UTS $(\mathrm{Y})$ & $\mathrm{X}^{2}$ & $\mathrm{Y}^{2}$ & XY \\
\hline PLTKM90001 & 73 & 84 & 5329 & 7056 & 6132 \\
\hline PLTKM90002 & 54 & 84 & 2916 & 7056 & 4536 \\
\hline PLTKM90003 & 63 & 84 & 3969 & 7056 & 5292 \\
\hline PLTKM90004 & 54 & 64 & 2916 & 4096 & 3456 \\
\hline PLTKM90005 & 82 & 84 & 6724 & 7056 & 6888 \\
\hline PLTKM90006 & 82 & 84 & 6724 & 7056 & 6888 \\
\hline PLTKM90007 & 100 & 96 & 10000 & 9216 & 9600 \\
\hline PLTKM90008 & 82 & 92 & 6724 & 8464 & 7544 \\
\hline PLTKM90009 & 100 & 88 & 10000 & 7744 & 8800 \\
\hline PLTKM90010 & 55 & 56 & 3025 & 3136 & 3080 \\
\hline PLTKM90011 & 82 & 76 & 6724 & 5776 & 6232 \\
\hline PLTKM90012 & 82 & 88 & 6724 & 7744 & 7216 \\
\hline PLTKM90013 & 82 & 84 & 6724 & 7056 & 6888 \\
\hline PLTKM90014 & 54 & 84 & 2916 & 7056 & 4536 \\
\hline PLTKM90015 & 91 & 88 & 8281 & 7744 & 8008 \\
\hline PLTKM90016 & 63 & 92 & 3969 & 8464 & 5796 \\
\hline PLTKM90017 & 91 & 84 & 8281 & 7056 & 7644 \\
\hline PLTKM90020 & 73 & 84 & 5329 & 7056 & 6132 \\
\hline PLTKM90021 & 72 & 60 & 5184 & 3600 & 4320 \\
\hline PLTKM90023 & 55 & 76 & 3025 & 5776 & 4180 \\
\hline
\end{tabular}

$\mathrm{r}_{\mathrm{xy}}$ kuis-2/UTS untuk kelas TI $2019=0.517353994$

Nilai Rata-rata kuis-2: 73.95, dari 20 mahasiswa

Tabel 4. Pengukuran Validitas nilai kuis 3 terhadap nilai UTS kelas DSI TI-2019

\begin{tabular}{|c|c|c|c|c|c|}
\hline Peserta & Kuis $3(\mathrm{X})$ & UTS $(\mathrm{Y})$ & $\mathrm{X}^{2}$ & $\mathrm{Y}^{2}$ & XY \\
\hline PLTKM90001 & 74 & 84 & 5476 & 7056 & 6216 \\
\hline PLTKM90002 & 68 & 84 & 4624 & 7056 & 5712 \\
\hline PLTKM90003 & 92 & 84 & 8464 & 7056 & 7728 \\
\hline PLTKM90004 & 68 & 64 & 4624 & 4096 & 4352 \\
\hline PLTKM90005 & 89 & 84 & 7921 & 7056 & 7476 \\
\hline PLTKM90006 & 89 & 84 & 7921 & 7056 & 7476 \\
\hline PLTKM90007 & 84 & 96 & 7056 & 9216 & 8064 \\
\hline PLTKM90008 & 89 & 92 & 7921 & 8464 & 8188 \\
\hline PLTKM90009 & 84 & 88 & 7056 & 7744 & 7392 \\
\hline PLTKM90010 & 84 & 56 & 7056 & 3136 & 4704 \\
\hline PLTKM90011 & 76 & 76 & 5776 & 5776 & 5776 \\
\hline PLTKM90012 & 89 & 88 & 7921 & 7744 & 7832 \\
\hline PLTKM90013 & 92 & 84 & 8464 & 7056 & 7728 \\
\hline PLTKM90014 & 84 & 84 & 7056 & 7056 & 7056 \\
\hline PLTKM90015 & 84 & 88 & 7056 & 7744 & 7392 \\
\hline PLTKM90016 & 76 & 92 & 5776 & 8464 & 6992 \\
\hline PLTKM90017 & 100 & 84 & 10000 & 7056 & 8400 \\
\hline PLTKM90020 & 84 & 84 & 7056 & 7056 & 7056 \\
\hline PLTKM90021 & 62 & 60 & 3844 & 3600 & 3720 \\
\hline PLTKM90023 & 92 & 76 & 8464 & 5776 & 6992 \\
\hline
\end{tabular}

rxy kuis-3/UTS untuk kelas TI $2019=0.415681538$

Nilai Rata-rata Kuis-3 : 83.1, dari 20 mahasiswa

Nilai Rata-rata UTS : 81.33, dari 20 mahasiswa 
Pengukuran peningkatan sebagai berikut. PAB untuk kuis 1 ke UTS $=37.66137956$, PAB untuk kuis 2 ke UTS $=9.135620312$ dan PAB untuk kuis 3 ke UTS $=-2.176318702$

\section{SIMPULAN DAN SARAN}

\section{Simpulan}

Peningkatan terjadi dari kuis tahap pertama ke tahap selanjutnya, kecuali dari tahap kuis 3 ke UTS. Pembuatan program sendiri diperlukan, karena kemampuan pengujian Kahoot dan Moodle terbatas. Sehingga dimungkinkan akan dapat dilakukan pengembangan aplikasi, baik untuk integrasi, maupun untuk penampilan soal.

Konsep kognitif memang berupa hipotesis, namun penggunaannya bermanfaat bagi pengembangan pembelajaran dan pendidikan. Dengan pendekatan multi perspektif diharapkan pola pembuatan soal akan lebih berkembang, tidak hanya berorientasi hafalan.

Penerapan konsep Retrieval Practice, relatif mudah dan murah untuk dilaksanakan. Hasilnya, peningkatan semangat belajar, cukup penting. Nilai yang termasuk rendah tersebut merupakan nilai yang diperoleh bagi mahasiswa yang berkebutuhan khusus.

\section{Saran}

Aplikasi sistem informasi pendukung penerapan Retrieval Practice, perlu dikembangkan dan disempurnakan lagi, terutama perlu diintegrasi dengan SIAKAD maupun dalam pengaturan waktu. Konsep psikologi kognitif perlu dikaji lebih lanjut, agar dapat meningkatkan kualitas bangunan pengetahuan dan pemahaman mahasiswa.

\section{Ucapan Terimakasih}

Atas bantuan langsung maupun tak langsung, saya sebagai peneliti mengucapkan terimakasih kepada instansi Risetdikti, yang mendanai penelitian ini. Terimakasih juga kepada temanteman dosen, Kepala Program Studi Teknik Informatika, dan Ketua dan Sekretaris Lembaga Penelitian dan Pengabdian pada Masyarakat Politeknik Kota Malang

\section{DAFTAR RUJUKAN}

[1] Pooja K. Agarwal, Ph.D., Henry L. Roediger, III, Ph.D., Mark A. McDaniel, Ph.D. ,Kathleen B. McDermott, Ph.D., How to Use Retrieval Practice to Improve Learning Washington University in St. Louis. (2013)

Available at:

https://firstliteracy.org/wp-content/uploads/2015/07/RetrievalPracticeGuide-for-FLWorkshop-on-Brain-Based-ESOL-Instruction.pdf

[Accessed 10 November 2019]

[2] Pooja K. Agarwal, Jason R. Finley, Nathan S. Rose and Henry L. RoedigerIII , Benefits from retrieval practice are greater for students with lower working memory capacity Washington University in St. Louis, St. Louis, MO, USA; MEMORY, 2017 VOL. 25, NO. 6, 764-771 (2011)

Available at:

http://dx.doi.org/10.1080/09658211.2016.1220579

http://pdf.poojaagarwal.com/Agarwal_etal_2017_Memory.pdf

[Accessed 10 November 2019]

[3] Edugyan, Educational Psychology, The Modal Model of Memory: Sensory, Shortterm, and Long-term Memory, (2017)

Available at:

http://www.edugyan.in/2017/03/modal-model-of-memory-sensory-short.html

[Accessed 10 November 2019]

[4] Luke Mastin, Sensory Memory, (2018) 
Available at:

http://www.lukemastin.com/humanmemory/types_sensory.html [Accessed 10 November 2019]

[5] Edugyan, Educational Psychology Processes in Long-Term Memory: Rehearsal, Elaboration, and Organization, (2011)

Available at:

http://www.edugyan.in/2017/03/processes-in-long-term-memory-rehearsal.html [Accessed 10 November 2019]

[6] Pooja K. Agarwal and Henry L. Roediger III, Expectancy of an open-book test decreases performance on a delayed closed-book test Washington University in St. Louis, St. Louis, MO, USA. MEMORY, 2011, 19 (8), 836 - 852, (2011)

Available at:

http://pdf.poojaagarwal.com/Agarwal_Roediger_2011_Memory.pdf

[Accessed 10 November 2019]

[7] Henry L. Roediger III, Pooja K. Agarwal, Mark A. McDaniel, and Kathleen B. McDermott, Test-Enhanced Learning in the Classroom: Long-Term Improvements From Quizzing. Washington University in St. Louis, (2011)

Journal of Experimental Psychology: Applied (C) 2011 American Psychological Association 2011, Vol. 17, No. 4, 382-395 1076-898X/11/\$12.00 DOI: $10.1037 / \mathrm{a} 0026252$

Available at:

https://www.researchgate.net/publication/51797070_Test-

Enhanced_Learning_in_the_Classroom_Long-Term_Improvements_From_Quizzing [Accessed 10 November 2019]

[8] Arikunto, Suharsimi, Jabar, Cepi Safruddin Abdul, Evaluasi program pendidikan : pedoman teoretis praktis bagi praktisi pendidikan, Jakarta: Bumi Aksara, (2009)

[9] Richard A. Krueger, Designing and Conducting Focus Group Interviews, University of Minnesota, Buford Ave.St. Paul, MN 55108 rkrueger@umn.edu October 1954

[10] Craik, F. I. M., \& Lockhart, R. S. Levels of processing: A framework for memory research. Journal of Verbal Learning and Verbal behavior, 11, 671-684, (1972)

[11] Craik, F.I.M., \& Tulving, E., Depth of processing and the retention of words in episodic memory. Journal of Experimental Psychology: General, 104, 268-294, (1975) 